\title{
Windings Design for Single-phase Induction Motors Base on 4- phase Induction Motor (Case study: identical windings design)
}

\author{
Zuriman Anthony ${ }^{1 *}$, Erhaneli Erhaneli ${ }^{1}$, Zulkarnaini Zulkarnaini ${ }^{1}$ \\ ${ }^{1}$ Electrical Engineering Department, Institut Teknologi Padang, Indonesia
}

\begin{abstract}
A 1-phase induction motor usually has a complicated windings design which compares to polyphase induction motor. In addition, a large capacitor start is required to operate the motor. It is an expensive way to operate the motor if it compare to polyphase induction motor. So, a new innovation method is required to make the motor more simple and cheaper. This research is purposed to study a new winding design for a single-phase capacitor motor. Winding design of the motor was conducted to a simple winding design like a 4-phase induction motor that has four identical windings. The comparator motor that use in this study was a Three-phase induction motor with data $1400 \mathrm{RPM}, 1.5 \mathrm{HP}, 50 \mathrm{~Hz}, 380 / 220 \mathrm{~V}, \mathrm{Y} / \Delta$, 2.74/4.7A, 4 poles, that had the same current rating which the proposed method. The result showed that the motor design on this proposed method could be operated at $88.18 \%$ power rating with power factor close to unity.
\end{abstract}

\section{Introduction}

The Induction motors usually used in many sectors, especially in industrial and home application, because this motor is simple and robust construction. At present, there are two types induction motor in application, threephase and single-phase motor. The three-phase motor is usually supplied by a 3-phase system, whereas a singlephase motor with a 1-phase system [1].

The 3-phase motors usually operate on a three-phase system. The motors are usually produced in high power ratings. They operate normally by using Three-phase power supply. The motors have 3 identical windings separated by 120 degrees electricity. The number of turns of each winding is equal, so that the motor can operate with a balanced current on each winding when the 3-phase balanced source is used in the motor [1-2]. In the development of operating system, the 3-phase motor had been operated on 1-phase power system [3-9]. The motor was operated on 1-phase power supply by installing some capacitors to the windings of the motor [3-8]. The modification technique was developed by adopting 2 windings principle of single-phase capacitor motor. Some evaluation methods had been developed by some research to find a simple method for analyzing the characteristics of the motor $[3,10]$.

Single-phase induction motor is a motor that usually produced at low power rating. The motor is operated on a single-phase supply and usually used in some home applications, such as fans, etc. The motor usually has 2 windings, auxiliary and main windings [1]. The motor will operate with better performance when capacitors are installed on the motor. These capacitors serve to produce the phase difference between the two windings (auxiliary and main windings) of the motor which aims to produce a large torque to the motor [1-2]. This method is called conventional method because the motor only has 2 windings. Although the performances the motor had been developed [11-14], the construction design of the winding of the motor still has the same with the conventional methods.

This paper is focused to study a new technique and construction of the winding of a single-phase capacitor motor. The motor has four windings that we called U, V, $\mathrm{W}$ and $\mathrm{X}$ windings. All of the windings are identical windings that have the same cross section area.

\section{Winding Design of Induction Motor}

\subsection{Three Phases Winding Design}

Three-phase induction motor has three identical windings that are separated from each other by 120 degrees. The design of the motor windings can be modeled as shown in Fig. 1.

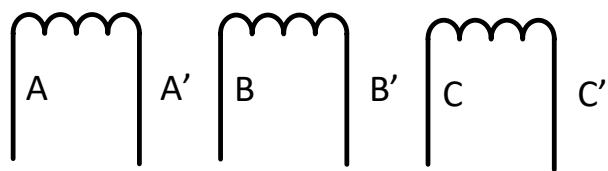

Fig. 1. Three phases windings design of a three-phase motor

The windings of a three-phase motor can be connected in two variation standards, Wye (Y) and delta $(\Delta)$ as shown in Fig. 2 and Fig. 3 respectively.

\footnotetext{
* Corresponding author: antoslah@gmail.com
} 


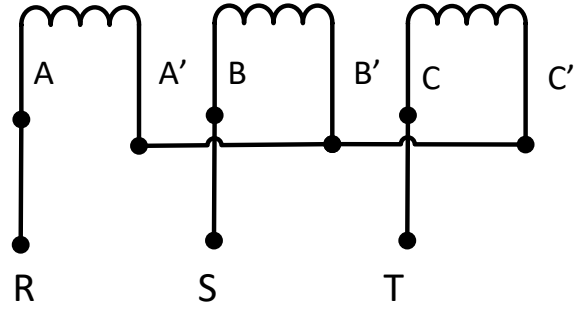

Fig. 2. Wye winding connection of a three-phase motor

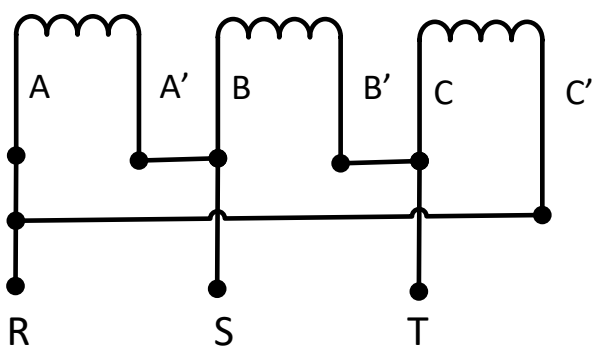

Fig. 3. Delta winding connection of a three-phase motor

Figs. 1, 2 and 3 show that the 3-phase motor has three identical windings, A (A to A'), B (B to B') and C (C to $\left.\mathrm{C}^{\prime}\right)$. The letters R, S and T in Figs. 2 and 3 are the spots for which a three-phase source is connected to supply the motor.

\subsection{Conventional 1-phase Capacitor Motor}

Single-phase capacitor motor usually has 2 windings. The windings are called main and auxiliary windings respectively. Both windings are usually used for starting. A 1-phase capacitor motor usually used capacitors that installed in series with one of the windings as shown in Fig. 4. Fig. 5 shows the windings design of a conventional 1-phase capacitor start capacitor run induction moto.

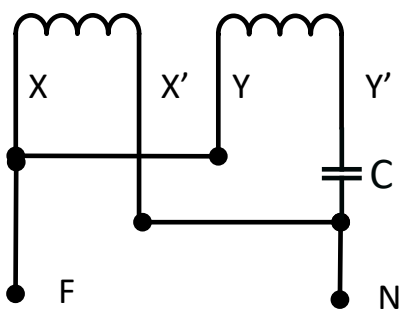

Fig. 4. Windings of a 1-phase capacitor motor

From the data shown in Fig. 4 and Fig. 5 can be explained that the letter $\mathrm{X}$ to $\mathrm{X}^{\prime}$ is main winding and $\mathrm{Y}$ to $\mathrm{Y}^{\prime}$ is auxiliary winding. $\mathrm{C}$ is capacitor installed at auxiliary winding in Fig. 4. $\mathrm{Cs}$ and $\mathrm{Cr}$ in Fig. 5 are the start capacitor and the run capacitor respectively. Letter ' $\mathrm{F}$ ' and ' $\mathrm{N}$ ' in Fig. 4 and Fig. 5 are line power and Neutral of the single-phase supply system respectively.

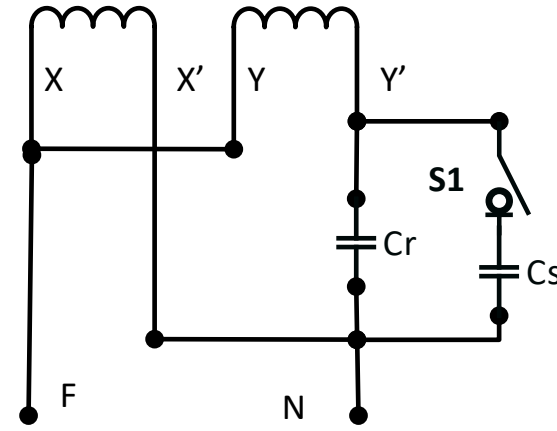

Fig. 5. Two windings of a conventional single-phase capacitor motor

\subsection{Four Phases Windings design}

Four phases windings design of the motor has four identical windings that are separated from each other by 90 degrees. The model of the windings design is shown in Fig. 6.

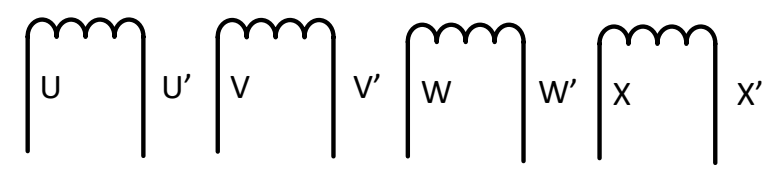

Fig. 6. Four phases windings design of the motor

\section{Research Method}

This study is proposed to show a new windings construction of a single-phase capacitor motor by using 4 phases windings design. The induction motor used as comparator for this study was a three-phase induction motor with data $1400 \mathrm{RPM}, 1.5 \mathrm{HP}, 50 \mathrm{~Hz}, 380 / 220 \mathrm{~V}$, $\mathrm{Y} / \Delta, 2.74 / 4.7 \mathrm{~A}, 4$ poles. The motor had 3 identical winding of $0.65 \mathrm{~mm}^{2}$ in size. The proposed method had 4 windings constructed in the stator that we mark as $U$, $\mathrm{V}, \mathrm{W}$ and $\mathrm{X}$ as shown in Fig. 7. The 3 windings (U, V, $\mathrm{W})$ are connected together and we call the auxiliary windings and the ' $\mathrm{X}$ ' windings is called the main winding. The windings of the proposed method were made the same size of $0,65 \mathrm{~mm}^{2}$ like an identical fourphase induction motor.

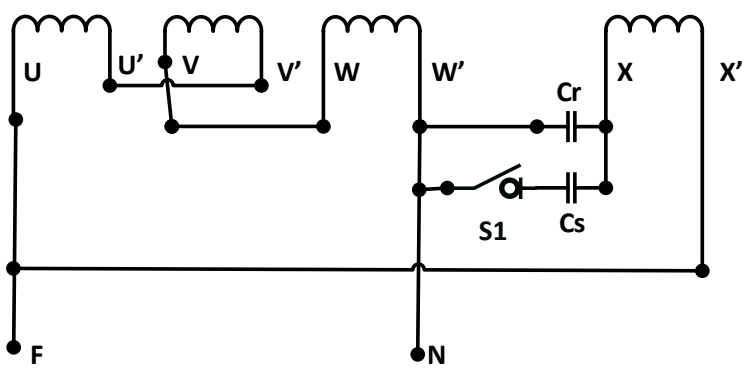

Fig. 7. Windings design on proposed motor

' $\mathrm{S} 1$ ' in Fig. 7 is a centrifugal switch that use to disconnect the start capacitor after the motor reach the running condition. 
Total capacitance of the capacitor (Cst) as shown in Fig. 7 can be calculated by using the formula published by Anthony [4] as follows.

$$
C s t=\frac{(0,1757) \cdot I_{N}}{(f) \cdot V_{L N}}(\text { Farad })
$$

The capacitance of the run capacitor $(\mathrm{Cr})$ can be calculated as follows.

$$
C r=\frac{I_{p h}}{(\omega) \cdot\left(A_{Z} \cdot V_{L N}\right)}=\frac{I_{p h}}{\left(A_{Z}\right) \cdot(2 \cdot \pi \cdot f) \cdot\left(V_{L N}\right)}(\text { Farad })
$$

Where:

$$
A_{Z}=\frac{N_{U}+N_{V}+N_{W}}{N_{X}}
$$

$I_{p h} \quad=$ rating current of the motor winding (A)

$V_{L N}=$ Line to neutral voltage $(\mathrm{V})$

$f=$ Frequency of the source power system $(\mathrm{Hz})$

$\mathrm{A}_{\mathrm{Z}}=$ Constanta of Zuriman Anthony

$\mathrm{N}_{\mathrm{U}}=$ total slots used by ' $\mathrm{U}$ ' windings

$\mathrm{N}_{\mathrm{V}}=$ total slots used by ' $\mathrm{V}$ ' windings

$\mathrm{N}_{\mathrm{W}}=$ total slots used by ' $\mathrm{W}$ ' windings

$\mathrm{N}_{\mathrm{X}}=$ total slots used by ' $\mathrm{X}$ ' windings

Further, the capacitance of the start capacitor (Cs) in the Fig. 7, can be calculated as follows.

$$
C s=C s t-C r(\text { Farad })
$$

The voltage ' $\mathrm{Vc}$ ' on the run capacitor and the reactive power donated by the run capacitor (VARc) can be calculated respectively as follows.

$$
\begin{gathered}
V c=A_{Z} \cdot V_{L N} \\
V A R c=\omega \cdot C r \cdot\left(V_{C}\right)^{2}=\left(A_{Z}\right)^{2} \cdot \omega \cdot C r \cdot\left(V_{L N}\right)^{2}
\end{gathered}
$$

The apparent power $(\mathrm{S})$ and the line current $\left(I_{L}\right)$ of the motor can be calculated by the following formula.

$$
S=V A R c
$$

The line current $\left(I_{L}\right)$ enters into the motor can be calculated as follows.

$$
I_{L}=\frac{S}{V_{L N}}
$$

When the motor is operated with a nominal winding current, the motor will operate with a power factor close to unity. Therefore, the power factor $(P F)$ and power input (Pin) of the motor can be defined as follows.

$$
\begin{gathered}
P F=\operatorname{Cos}(\varphi)=0,98 \\
\text { Pin }=\operatorname{S.COS}(\varphi)
\end{gathered}
$$

\section{Results and Discussion}

The 1-phase proposed motor was tested in the laboratory. The characteristics of the motor then compared to the characteristics of the comparator motor. The result of this study can be explained as follows.

\section{(1) Output Characteristic}

The output power characteristic of the motors is shown in Fig. 8.

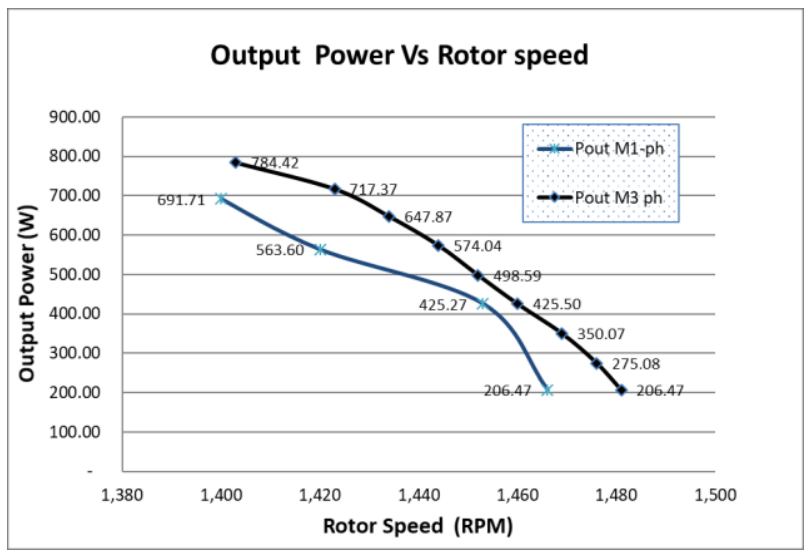

Fig. 8. Output power characteristic of the motors

From the Fig. 8 can be explained that the Output Power of the proposed motor (Pout M1-ph) is $691.71 \mathrm{~W}$ that is $88.18 \%$ Output Power of the comparator motor (Pout M3 ph). So, the proposed motor could operate almost close to the rating power of the comparator motor.

(2) Power Factor Characteristic

The power factor characteristics of the motors are shown in Fig. 9.

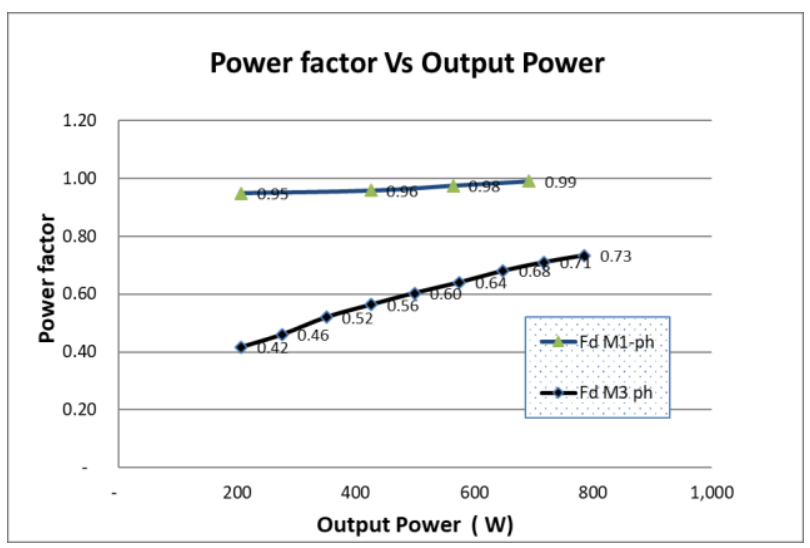

Fig. 9. Power factor characteristics of the motors

From the data in Fig. 9 can be seen that the power factor of the proposed method (Fd M1-ph) always between 0.95 and 0.99 that was better than the threephase induction motor. (Fd M3 ph). That is because the capacitor used in equation (2) is set to improve power factor to become close to unity.

(3) Efficiency Characteristic 
The efficiency characteristics of the motors are shown in Fig. 10

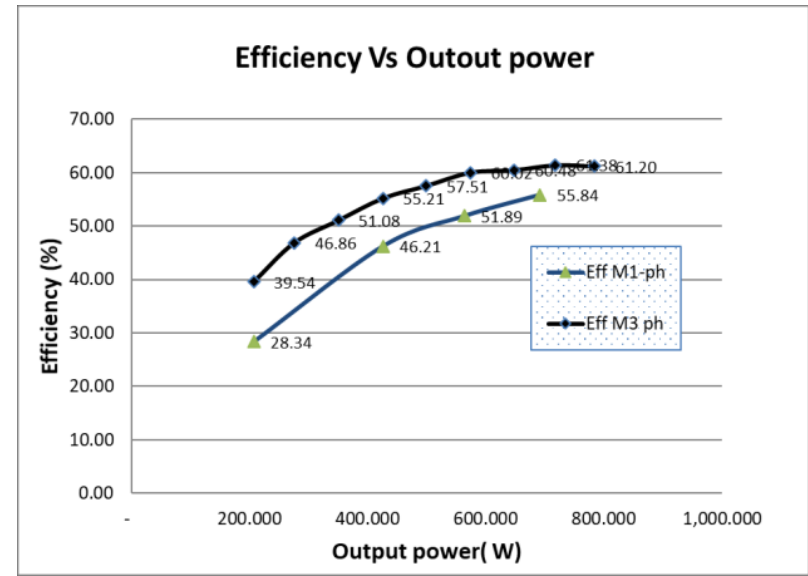

Fig. 10. Efficiency characteristics of the motors

From the data shown in Fig. 10 can be explained that the efficiency of the 3-phase motor (Eff M3 ph) is better than the proposed motor (Eff M1-ph). That is because the proposed motor uses the same size of the winding $\left(0.65 \mathrm{~mm}^{2}\right)$ both the main and the auxiliary windings. Of course, the current of both the main and the auxiliary is limited not to higher than the current rating of the windings. So, the proposed motor did not work optimally. So, for better performances of the motor, the auxiliary windings of the proposed motor should be bigger than the main windings.

\section{Conclusions and recommendations}

This study is proposed to show a new winding design for a single-phase capacitor motor by using 4 phases winding design. The proposed motor could be operated at $88.18 \%$ Output Power of the comparator motor, on power factor close to unity. But, the efficiency of the proposed motor lower than the comparator motor because all windings of the proposed motor is the same in size. So, for better performances of the motor, the auxiliary windings of the proposed motor should be bigger than the main windings. It will be discussed in the next topic of papers.

\section{Acknowledgements}

We would like to thank very much to the team of the laboratory of electrical engineering of the 'Institute of Technology Padang (Institut Teknologi Padang)' that helped us in research in the laboratory. We would also like to thank for 'Kopertis Wilayah $\mathrm{X}^{\prime}$ and 'Directorate for Research and Community Service, Directorate General for Research and Development at the Ministry of Research, Technology and Higher Education' Republic of Indonesia whose helped fund this research in accordance with the research contract number 320/27.O10.5/PN/II/2018.

\section{References}

1. P. C. Sen, Principles of Electrical Machines and Power Electronics. (John Wiley \& Sons, 1996).

2. S. J. Chapman, Elecrical Machinery Fundamentals. (McGraw-Hill, 2005).

3. Z. Anthony, Equivalent Circuits for the M31D-ZA Motor "s Method ( Case Studies: Currents and Power Factor of the motor ). IJETT 25, 49-52 (2015).

4. Z. Anthony, A Simple Method For Operating The Three-Phase Induction Motor On Single Phase Supply ( For Wye Connection Standard ). IJETT 5, 13-16 (2013).

5. Z. Anthony, A Simple Method for Operating the Delta Connection Standard of the 3-phase Induction Motor on Single Phase Supply. IJETT 15, 444-447 (2014).

6. Z. Anthony, Analyzing Characteristics of the Sheda " s Method for Operating the 3-phase induction Motor on Single Phase Supply ( Case studies: output power and efficiency of the motor ). IJETT 33, 175-179 (2016).

7. Y. A. Al-turki, H. Al-umari, Application of the reference frame theory to the dynamic analysis of a three-phase induction motor fed from a single-phase supply. Elsevier 53, 149-156 (2000).

8. N. A. Ahmed, Three-phase induction motor operating from single-phase supply with an electronically controlled capacitor. Electr. Power Syst. Res. 73, 121-128 (2005).

9. A. K. Adapa, V. John, Active Phase-Converter for Operation of Three-Phase Induction Motors on Single-Phase Grid. (2016).

10. Z. Anthony, E. Erhaneli, B. Busran, A new equivalent circuit of the three-phase induction motor (case studies: Current and power factor of the motor). ARPN J. Eng. Appl. Sci. 12, (2017).

11. T. H. Liu, Maximum torque control with a controlled capacitor for a single-phase induction motor. IEEE Trans. Ind. Electron. 42, 17-24 (1995).

12. T. Liu, M. Lin, H. A. Wu, Single phase induction motor drive with improved performance. 47, 29-38 (1998).

13. K. Makowski, Determination of performance characteristics of a single-phase shaded pole induction motor by circuit-field method. Electr. Eng. 84, 281-286 (2002).

14. E. Muljadi, Y. Zhao, Y., T. A. Lipo, T. H. Liu, Adjustable ac capacitor for a single-phase induction motor. IEEE Trans. Ind. Appl. 29, 479-485 (1993). 